NOTICE: this is the author's version of a work that was accepted for publication in Gynecologic Oncology. Changes resulting from the publishing process, such as peer review, editing, corrections, structural formatting, and other quality control mechanisms may not be reflected in this document. Changes may have been made to this work since it was submitted for publication. A definitive version was subsequently published in Gynecologic Oncology, Vol. 129 (2013). DOI: http://dx.doi.org/10.1016/j.ygyno.2013.03.016 


\title{
Preserved foods associated with increased risk of ovarian cancer
}

\author{
Andy H. Lee, Dada Su, Maria Pasalich, Colin W. Binns \\ School of Public Health, Curtin University, Perth, WA, Australia.
}

Email:

andy.lee@curtin.edu.au, alicewater@live.com.au, maria.pasalich@hotmail.com,

c.binns@curtin.edu.au

\section{Corresponding author:}

Professor Andy H. Lee

School of Public Health

Curtin Health Innovation Research Institute

Curtin University

GPO Box U 1987

Perth, WA, 6845

Australia

Phone: +61-8-92664180

Fax: +61-8-92662958

Email: Andy.Lee@ curtin.edu.au 


\section{ABSTRACT}

Objective: To investigate the association between consumption of preserved foods and risk of epithelial ovarian cancer in southern Chinese women.

Methods: A hospital-based case-control study was undertaken in Guangzhou, Guangdong Province, from 2006 to 2008. Participants were 500 incident epithelial ovarian cancer patients and 500 controls, with a mean age 59 years. Information on habitual food consumption was obtained by face-to-face interview using a validated and reliable food frequency questionnaire. Logistic regression analyses were performed to assess the association between preserved foods intake and the ovarian cancer risk.

Results: The ovarian cancer patients consumed more preserved foods (median 15.5, interquartile range (IQR) $18.2 \mathrm{~g} /$ day) than controls (median 13.8, IQR $20.5 \mathrm{~g} /$ day), $\mathrm{p}<0.001$. The adjusted odds ratios of ovarian cancer was 1.78 (95\% confidence interval 1.35 to 2.34 ) for women consuming more than $13.5 \mathrm{~g}$ of preserved vegetables and preserved meats per day relative to those below. Similar two-fold increases in risk at high level of intake were also evident for serous and mucinous subtypes of epithelial ovarian tumours.

Conclusion: Intake of preserved foods was positively associated with the incidence of epithelial ovarian cancer in southern Chinese women.

Word count: 189

Keywords: China; Ovarian cancer; Preserved foods 


\section{INTRODUCTION}

Ovarian cancer has the eighth highest incidence of all cancers in women, with approximately 225,000 new cases reported worldwide in 2008 [1]. The disease ranks second in terms of gynaecological malignancies [2] and is the 7th most common cause of cancer-related deaths among women [1]. Currently, there is no effective screening method available for detection [3]. Symptoms are vague, non-specific, and generally appear in the advanced stages of the disease, contributing to the high case-fatality ratio [4].

There is considerable geographic variation in the incidence of ovarian cancer, with higher rates in developed countries. The age-standardised rate in China is low at 3.8 per 100,000 women, when compared to the USA (8.8) and Europe (10.1) [1]. The large difference in incidence rates between countries has generated interest in the role of dietary and lifestyle factors in ovarian cancer aetiology, besides genetic and familial risk factors, the knowledge of which may contribute to the primary prevention of the disease.

Preserved food products are widely consumed in many countries. Previous research has suggested their consumption may be linked to the development of a number of cancers, including cancer of the prostate, oesophagus, colorectal, and stomach [5-8]. In particular, a case-control study in China found that high intake of preserved (salted) vegetables can increase the risk of ovarian cancer by more than three-fold [9]. Similarly, a recent analysis of two Australian case-control studies revealed a significant $18 \%$ increased risk for women with the highest intake of processed meat [10]. Most other epidemiological studies have reported increased risk with greater consumption of preserved foods, albeit non-significant results [8, 11-14], with some observing lack of association [15] or little reduction in risk [16]. 
Several types of preserved foods are popular in southern China, including preserved meats, pickled vegetables and salted fish. In view of the limited epidemiological evidence, the present study aimed to assess the association between habitual preserved foods consumption and the risk of ovarian cancer among southern Chinese women.

\section{METHODS}

\section{Study design and subjects}

A case-control study was conducted in Guangzhou, the capital city of Guangdong Province of southern China, between August 2006 and July 2008. Subjects were recruited from four public hospitals, namely, The Overseas Hospital (affiliated with Jinan University), Zhujiang Hospital, General Hospital of Guangzhou Military Command, and Second Affiliated Hospital of Zhongshan University. Cases were incident patients who had been histopathologically diagnosed with epithelial ovarian cancer within the past 12 months. Controls were recruited from inpatient wards of the Departments of ophthalmology, orthopedic, respiratory disease, gastroenterology and physiotherapy. To be eligible, all subjects were required to be under 75 years of age and have resided in the metropolitan Guangzhou area for at least the past ten years.

Potential cases were identified by searching the daily census of the hospitals. To ensure complete ascertainment of cases, all hospital medical records and laboratory pathology reports were reviewed during the recruitment period. Pathological diagnoses were based on the International Histological Classification of Ovarian Tumors [17]. Patients were excluded when ovarian cancer was histopathologically confirmed to be neither the primary nor final diagnosis, or if they confessed to have memory problems affecting their recall of past events. 
Of the total 504 cases consecutively recruited from the four hospitals, 500 patients with cancer of the ovary consented to participate and were capable of being interviewed.

During the same period, 512 eligible controls were identified and approached to be interviewed. These women were frequency matched to cases by age ( \pm 5 years). Exclusion criteria for controls were (1) previous diagnosis of ovarian cancer or other malignant diseases; (2) a history of bilateral oophorectomy; (3) having memory problems; (4) on longterm modification of diet for medical reasons; in addition to non-residency and advanced age exceeding 75 years. Subjects to be approached for inclusion as controls were initially screened using the hospital daily census sheets. A selection of ward and patient ID was made using random numbers each day whenever more control subjects appeared to be available than could be interviewed. All eligible inpatients had their diagnosis subsequently confirmed by histopathological reports to avoid misclassification of the case-control status. This systematic selection process was adopted throughout the recruitment period. Twelve women who declined the interview or not satisfying the eligibility conditions were later excluded, resulting in a final sample of 500 controls available for analysis. No statistically significant differences were found between the two groups in terms of age and main demographic variables.

\section{Interview}

An appointment for face-to-face interview at the ward was arranged with each participant after consulting the nursing staff to avoid interference with treatment. Whenever possible, subjects were interviewed in the presence of their next-of-kin to help the recall of dietary habits. All participants gave formal consent before the interview. They were also assured of confidentiality and their right to withdraw without prejudice. Each interview, conducted in 
either Mandarin or the Cantonese dialect, took on average 45 minutes to complete. All participants were blinded to the study hypothesis. The project protocol was approved by the participating hospitals, the doctors-in-charge of the relevant wards, and the Human Research Ethics Committee of Curtin University (approval number HR 78/2006).

\section{Questionnaire and exposure measurements}

A structured questionnaire was administered to obtain demographic and lifestyle characteristics including age, weight $(\mathrm{kg})$, height $(\mathrm{m})$, education level, smoking status and alcohol consumption, as well as reproductive history, hormonal status and heredity. Selfreported data were cross-checked with medical records whenever available.

Participants were also requested to estimate their average time engaged in physical activities using validated questions [18]. Intensity was classified by the amount of energy or effort a person expends in performing the activity. Physical activity at each intensity level was quantified in terms of metabolic equivalent tasks (MET)-hours per week, with intensity codes 7.5, 6.0 and 4.5 MET assigned to strenuous sports, vigorous work and moderate activity, respectively. Total physical activity was then calculated by summing the product of MET score and activity duration over the three intensity levels.

Information on habitual food and beverage consumption was obtained using a 125 -item semiquantitative food frequency questionnaire developed and tested for the southern Chinese population $[19,20]$. This validated instrument covered commonly consumed foods (including preserved products) in southern China. Frequency and amount of intake were recorded in detail. The reference recall period for dietary variables was set at five years before diagnosis for cases and five years before interview for controls. The energy content of each food or 
beverage item was obtained from the Chinese food composition tables [21]. We then estimated participant's total energy intake (kcal) by summing the energy intake across individual items consumed.

\section{Statistical analysis}

Descriptive statistics were first used to summarize the sample characteristics. Total preserved foods intake (g/day) was defined as the sum of daily consumption of preserved meats (sausage, ham, salted duck egg, salted fish) and preserved vegetables (dried turnip, salted mustard, pickled vegetables, pickled Chinese cabbage). For the comparison of intake between case and control groups, median (interquartile range) and Mann-Whitney tests were applied in view of the skewed distributions of these consumption variables.

Unconditional logistic regression analyses were then performed to investigate the effects of habitual preserved foods consumption on the ovarian cancer risk. Each consumption variable was dichotomized into low and high levels of exposure based on the corresponding $50^{\text {th }}$ percentile among controls, due to the relatively low daily intake by the control group. To investigate the risk of ovarian cancer by specific histologic subtype, we compared selected case subtype to the entire control group using adjusted odds ratios (OR) and associated 95\% confidence intervals (CI). Confounding variables included in the logistic regression models were age at interview (years), parity, oral contraceptive use (never, ever), body mass index (5 years ago), menopausal status (pre, post), education level (none or primary, secondary, vocational or tertiary), tobacco smoking (never, ever), alcohol drinking (no, yes), marital status (never married, married, widowed or divorced or separated), physical activity (METhours/week), total energy intake (kcal/day), and family history of ovarian or breast cancer 
(no, yes). These variables were either established or plausible risk factors from the literature. All statistical analyses were undertaken using the SPSS package version 20.

\section{RESULTS}

Table 1 gives the distribution of histologic subtypes of epithelial ovarian tumours. Half of all case tumours were classified as serous, and mucinous tumours comprised $16 \%$ of the cases. Table 2 presents characteristics of the sample by case-control status. The participants were 59 years of age on average and predominantly post-menopausal. Most of them had attained secondary school education or above, were non-smokers and seldom drank alcoholic beverages on a regular basis. Very few women had a family history of ovarian or breast cancer. However, women with ovarian cancer tended to have less oral contraceptive use and lower parities but higher mean body mass index than their counterparts without the disease. They also appeared to be less physically active in daily life.

Table 3 compares habitual preserved foods consumption between case and control groups. The ovarian cancer patients reported higher intake levels of preserved foods, especially preserved vegetables, than the control subjects. The differences were statistically significant according to Mann-Whitney tests. Table 4 summarizes the results of logistic regression analyses. Substantial increases in ovarian cancer risk were evident for high consumptions of preserved foods. Overall, the adjusted OR of ovarian cancer was 1.78 (95\% CI 1.35 to 2.34) among women consuming over $13.5 \mathrm{~g}$ of preserved vegetables and preserved meats per day, $p<0.001$. Similar two-fold increases in risk were also evident for serous and mucinous subtypes of epithelial ovarian tumours, with the exception of preserved meats for the mucinous subtype. Analyses were not performed for other histologic subtypes due to the low number of cases available. 


\section{DISCUSSION}

A positive association was found between the intake of preserved foods and the risk of epithelial ovarian cancer among southern Chinese women. The risk was particularly high for preserved vegetables, with more than two-fold increase in risk for consuming over 2 grams per day. Our findings are in partial agreement with a previous case-control study conducted in Hangzhou, China, which observed a positive association between pickled vegetable intake and ovarian cancer risk, yet a non-significant decrease in risk for preserved meat [9]. They also support the results of three cohort studies $[8,13,14]$ and two earlier case-control studies $[10,12]$. Furthermore, a meta-analysis of seven epidemiological studies (four case-control studies and three cohort studies) reported that women with the highest intake of preserved foods had a $20 \%$ greater risk of ovarian cancer [10].

Preserved foods generally contain large amounts of nitrates and nitrites which may act as the precursors for the generation of $N$-nitroso compounds [22, 23]. These compounds are mutagenic and considered to be potential carcinogens [24, 25]. Processed meats also contribute to the formation of heterocyclic amines [26] which are carcinogenic in animal models. In addition, they contain saturated fat which has been linked to carcinogenesis [27]. The processing and preservation of vegetables may reduce the levels of antioxidants, vitamins and minerals which are thought to be responsible for the anti-cancer effects of vegetables [11].

In this study, a standardized identification procedure was implemented which ensured that ascertainment of cases was maximized and complete. To avoid misclassification of the casecontrol status, we recruited only incident patients who had been histopathologically 
diagnosed with epithelial ovarian cancer within the past 12 months, and all controls had been carefully screened and subsequently confirmed with pathology. A high response rate (98\%) was achieved in the recruitment of inpatients through assistance by the medical doctors and full support from the nursing staff. Habitual food consumption was measured using a validated and reliable questionnaire specifically developed for the southern Chinese population, with information on frequency and quantity of intake recorded in detail. To determine and ascertain the effect of preserved foods, information on other exposures and confounding factors such as tobacco smoking, alcohol drinking and physical activity was also collected. It is possible that some ovarian cancer patients may modify their dietary habits since the onset of the disease. To avoid reverse causation, the reference period for habitual preserved foods consumption was set at five years before diagnosis for cases and five years before interview for controls. Moreover, no participant reported any change in eating habits for medical reasons within the past five years.

A major limitation of this study concerns the inherent retrospective cross-sectional design so that any cause-effect relationship could not be established. Although the recall of habitual preserved foods consumption should not be affected by the case-control status, dietary assessment was based on self-report so that responses from participants would inevitably incur some recall error. Therefore, face-to-face interviews were conducted in the presence of their next-of-kin to help memory recall and to improve the accuracy of their answers. Selection bias was unavoidable because all participants were voluntary and the hospital-based controls were not randomly selected from the community. Nevertheless, the four participating hospitals serve the entire catchment region so that our subjects were still representative of the target population. Recruitment bias was also minimized by sampling from different hospitals. Information bias and recall bias were unlikely because all participants were blind to the study 
hypothesis, while the detrimental effects of preserved food products on ovarian cancer have not been established in southern China at the time of interview. Finally, residual confounding might still exist even though established risk factors have been controlled for in the multivariable logistic regression analyses. There is no evidence from the literature supporting consumption of preserved foods as a marker of unhealthy lifestyle among southern Chinese women.

In conclusion, a positive association was found between habitual preserved foods intake and ovarian cancer incidence in southern China. Further prospective cohort studies are required to confirm the effects of long term consumption. In the meantime, women are recommended to minimize the intake of preserved food products to avoid the apparent increase in ovarian cancer risk.

\section{ACKNOWLEDGEMENTS}

We gratefully acknowledge the willing cooperation given by the patients and medical and nursing staff from the participating hospitals.

\section{CONFLICT OF INTEREST STATEMENT}

The authors declare that there are no conflicts of interest.

Word Count: 2,340 


\section{REFERENCES}

[1] Ferlay J, Shin H, Bray F, Forman D, Mathers C, Parkin D. Cancer incidence and mortality worldwide. In. Lyon, France: International Agency for Research on Cancer; 2010; Available from: http://globocan.iarc.fr.

[2] Sankaranarayanan R, Ferlay J. Worldwide burden of gynaecological cancer: the size of the problem. Best Pract Res Clin Obstet Gynaecol 2006; 20:207-25.

[3] Freedman J. Ovarian Cancer: Current and Emerging Trends in Detection and Treatment. Rosen Publishing Group; 2009.

[4] Buys SS, Partridge E, Black A, Johnson CC, Lamerato L, Isaacs C, et al. Effect of screening on ovarian cancer mortality: the Prostate, Lung, Colorectal and Ovarian (PLCO) Cancer Screening Randomized Controlled Trial. JAMA 2011; 305:2295-303.

[5] Jian L, Zhang DH, Lee AH, Binns CW. Do preserved foods increase prostate cancer risk? Br J Cancer 2004; 90:1792-5.

[6] Gao YT, McLaughlin JK, Gridley G, Blot WJ, Ji BT, Dai Q, et al. Risk factors for esophageal cancer in Shanghai, China. II. Role of diet and nutrients. Int J Cancer 1994; 58:197-202.

[7] Ji BT, Chow WH, Yang G, McLaughlin JK, Zheng W, Shu XO, et al. Dietary habits and stomach cancer in Shanghai, China. Int J Cancer 1998; 76:659-64.

[8] Cross AJ, Leitzmann MF, Gail MH, Hollenbeck AR, Schatzkin A, Sinha R. A prospective study of red and processed meat intake in relation to cancer risk. PLoS Med 2007; 4:e325.

[9] Zhang M, Yang ZY, Binns CW, Lee AH. Diet and ovarian cancer risk: a case-control study in China. Br J Cancer 2002; 86:712-7. 
[10] Kolahdooz F, van der Pols JC, Bain CJ, Marks GC, Hughes MC, Whiteman DC, et al. Meat, fish, and ovarian cancer risk: Results from 2 Australian case-control studies, a systematic review, and meta-analysis. Am J Clin Nutr 2010; 91:1752-63.

[11] Yen M-l, Yen BL, Bai C-h, Lin RS. Risk factors for ovarian cancer in Taiwan: a casecontrol study in a low-incidence population. Gynecol Oncol 2003; 89:318-24.

[12] Bosetti C, Negri E, Franceschi S, Pelucchi C, Talamini R, Montella M, et al. Diet and ovarian cancer risk: a case-control study in Italy. Int J Cancer 2001; 93:911-5.

[13] Larsson SC, Wolk A. No association of meat, fish, and egg consumption with ovarian cancer risk. Cancer Epidemiol Biomarkers Prev 2005; 14:1024-5.

[14] Schulz M, Nothlings U, Allen N, Onland-Moret NC, Agnoli C, Engeset D, et al. No association of consumption of animal foods with risk of ovarian cancer. Cancer Epidemiol Biomarkers Prev 2007; 16:852-5.

[15] Pan SY, Ugnat A-M, Mao Y, Wen SW, Johnson KC, Canadian Cancer Registries Epidemiology Research Group. A case-control study of diet and the risk of ovarian cancer. Cancer Epidemiol Biomarkers Prev 2004; 13:1521-7.

[16] Gilsing AMJ, Weijenberg MP, Goldbohm RA, van den Brandt PA, Schouten LJ. Consumption of dietary fat and meat and risk of ovarian cancer in the Netherlands Cohort Study. Am J Clin Nutr 2011; 93:118-26.

[17] Heintz AP, Odicino F, Maisonneuve P, Quinn MA, Benedet JL, Creasman WT, et al. Carcinoma of the ovary. FIGO (International Federation of Gynecology and Obstetrics) 26th Annual Report on the Results of Treatment in Gynecological Cancer. Int J Gynaecol Obstet 2006; 95 Suppl 1:S161-92.

[18] Jian L, Shen ZJ, Lee AH, Binns CW. Moderate physical activity and prostate cancer risk: a case-control study in China. Eur J Epidemiol 2005; 20:155-60. 
[19] Ke L, Toshiro T, Fengyan S, Ping Y, Xiaoling D, Kazuo T. Relative validity of a semiquantitative food frequency questionnaire versus 3 day weighed diet records in middleaged inhabitants in Chaoshan area, China. Asian Pac J Cancer Prev 2005; 6:376-81.

[20] Song FY, Toshiro T, Li K, Yu P, Lin XK, Yang HL, et al. Development of a semiquantitative food frequency questionnaire for middle-aged inhabitants in the Chaoshan area, China. World J Gastroenterol 2005; 11:4078-84.

[21] Yang Y, Wang G, Pan X. China Food Composition Table. China: The Institute of Nutrition and Food Safety, Chinese Center for Disease Control and Prevention. Peking University Medical Press; 2002.

[22] Armstrong B, Doll R. Environmental factors and cancer incidence and mortality in different countries, with special reference to dietary practices. Int J Cancer 1975; $15: 617-31$

[23] O'Neill IK, Chen J, Bartsch H. Relevance to human cancer of N-nitroso compounds, tobacco smoke and mycotoxins: International Agency for Research on Cancer; 1991.

[24] Schmähl D, Habs M. Carcinogenicity of N-nitroso compounds. Oncology 1980; $37: 237-42$.

[25] Lijinsky W. Nitroso compounds in the diet. Mutat Res 1999; 443:129-38.

[26] Rohrmann S, Hermann S, Linseisen J. Heterocyclic aromatic amine intake increases colorectal adenoma risk: findings from a prospective European cohort study. Am J Clin Nutr 2009; 89:1418-24.

[27] Genkinger JM, Hunter DJ, Spiegelman D, Anderson KE, Beeson WL, Buring JE, et al. A pooled analysis of 12 cohort studies of dietary fat, cholesterol and egg intake and ovarian cancer. Cancer Causes Control 2006; 17:273-85. 


\section{TABLE LEGEND}

Table 1. Distribution of histologic subtypes of epithelial ovarian tumours among cases

Table 2. Characteristics of participants by case-control status

Table 3. Comparison of preserved foods consumption between case and control groups

Table 4. Adjusted odds ratios (95\% confidence intervals) of epithelial ovarian cancer risk for preserved foods intake in southern Chinese women

Table 1.

\begin{tabular}{|l|l|}
\hline Pathological diagnosis & $\mathrm{n}(\%)$ \\
\hline Serous cystadenocarcinoma & $250(50.0 \%)$ \\
\hline Mucinous cystadenocarcinoma & $80(16.0 \%)$ \\
\hline Endometrioid cystadenocarcinoma & $19(3.8 \%)$ \\
\hline Mixed epithelial cystadenocarcinoma & $13(2.6 \%)$ \\
\hline Undifferentiated carcinoma & $59(11.8 \%)$ \\
\hline Borderline malignancy & $65(13.05)$ \\
\hline Clear cell carcinoma & $7(1.4 \%)$ \\
\hline Transitional cell carcinoma & $4(0.8 \%)$ \\
\hline Malignant Brenner's tumour & $3(0.6 \%)$ \\
\hline
\end{tabular}


Table 2.

\begin{tabular}{|c|c|c|c|}
\hline Variable & $\begin{array}{l}\text { Cases } \\
\mathrm{n}(\%)\end{array}$ & $\begin{array}{c}\text { Controls } \\
\text { n }(\%)\end{array}$ & $\mathrm{p}^{\mathrm{a}}$ \\
\hline Marital status & & & 0.83 \\
\hline Never married & $7(1.4 \%)$ & $8(1.6 \%)$ & \\
\hline Married & $449(89.8 \%)$ & $443(88.6 \%)$ & \\
\hline Widowed/divorced/separated & $44(8.8 \%)$ & $49(9.8 \%)$ & \\
\hline Education level & & & 0.90 \\
\hline None/primary & $204(40.8 \%)$ & $197(39.4 \%)$ & \\
\hline Secondary & $171(34.2 \%)$ & $175(35.0 \%)$ & \\
\hline Vocational/tertiary & $125(25.0 \%)$ & $128(25.6 \%)$ & \\
\hline Smoking status & & & 0.49 \\
\hline Never & $481(96.2 \%)$ & $485(97.0 \%)$ & \\
\hline Ever & $19(3.8 \%)$ & $15(3.0 \%)$ & \\
\hline Alcohol drinking & & & 0.16 \\
\hline No & $352(70.4 \%)$ & $372(74.4 \%)$ & \\
\hline Yes & $148(29.6 \%)$ & $128(25.6 \%)$ & \\
\hline Parity & & & $<0.01$ \\
\hline 0 & $8(1.6 \%)$ & $14(2.8 \%)$ & \\
\hline 1 & $172(34.4 \%)$ & $143(28.6 \%)$ & \\
\hline 2 & $219(43.8 \%)$ & $176(35.2 \%)$ & \\
\hline$\geq 3$ & $101(20.2 \%)$ & $167(33.4 \%)$ & \\
\hline Oral contraceptive use & & & $<0.01$ \\
\hline Never & $417(83.4 \%)$ & $380(76.0 \%)$ & \\
\hline Ever & $83(16.6 \%)$ & $120(24.0 \%)$ & \\
\hline
\end{tabular}




\begin{tabular}{|c|c|c|c|}
\hline Menopausal status & & & 0.24 \\
\hline Pre & $28(5.6 \%)$ & $20(4.0 \%)$ & \\
\hline Post & $472(94.4 \%)$ & $480(96.0 \%)$ & \\
\hline Family history of ovarian or breast cancer & & & 0.39 \\
\hline No & $480(96.0 \%)$ & $485(97.0 \%)$ & \\
\hline Yes & $20(4.0 \%)$ & $15(3.0 \%)$ & \\
\hline Age at interview (years): mean (SD) & $59.07(5.68)$ & $59.71(6.46)$ & 0.10 \\
\hline Body mass index (5 years ago, kg/m $\left.{ }^{2}\right):$ & $21.70(2.54)$ & $21.12(2.28)$ & $<0.01$ \\
mean (SD) & & & \\
\hline Physical activity (MET-hours/week): & $16.21(14.1)$ & $18.84(13.0)$ & $<0.01$ \\
\hline mean (SD) & & & \\
\hline
\end{tabular}

${ }^{a}$ Chi-square or t-test for difference between cases and controls 
Table 3.

\begin{tabular}{|l|c|c|c|c|}
\hline \multirow{2}{*}{ Daily intake (g) } & \multicolumn{3}{|c|}{ Cases } & Controls \\
& All & Serous & Mucinous & \\
& median (IQR) & median (IQR) & median (IQR) & median (IQR) \\
\hline Total preserved foods & $15.5^{* *}$ & $16.6^{* *}$ & $14.6^{*}$ & 13.8 \\
& $(18.2)$ & $(17.7)$ & $(15.4)$ & $(20.5)$ \\
\hline Preserved vegetables & $3.6^{* *}$ & $3.6^{* *}$ & $4.0^{* *}$ & 1.8 \\
& $(8.9)$ & $(8.9)$ & $(8.9)$ & $(10.7)$ \\
\hline Preserved meats & 8.9 & $11.1^{*}$ & 8.4 & $(7.7)$ \\
\hline
\end{tabular}

$* \mathrm{p}<0.05, * * \mathrm{p}<0.001$ for Mann-Whitney test between cases and controls 
Table 4.

\begin{tabular}{|c|c|c|c|c|c|c|c|}
\hline \multirow{3}{*}{\begin{tabular}{|l|} 
\\
$\begin{array}{l}\text { Daily } \\
\text { intake }(\mathrm{g})\end{array}$
\end{tabular}} & \multicolumn{6}{|c|}{ Cases } & \multirow{3}{*}{ 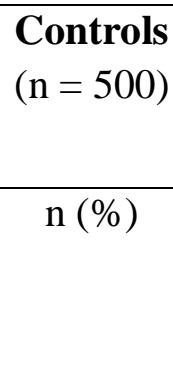 } \\
\hline & \multicolumn{2}{|c|}{ All $(n=500)$} & \multicolumn{2}{|c|}{ Serous $(n=250)$} & \multicolumn{2}{|c|}{ Mucinous $(n=80)$} & \\
\hline & $\mathrm{n}(\%)$ & $\begin{array}{l}\text { Adjusted } \\
\text { OR }^{\mathrm{a}} \\
(95 \% \mathrm{CI})\end{array}$ & $\mathrm{n}(\%)$ & $\begin{array}{l}\text { Adjusted } \\
\text { OR }^{\mathrm{a}} \\
(95 \% \mathrm{CI})\end{array}$ & $\mathrm{n}(\%)$ & $\begin{array}{l}\text { Adjusted } \\
\text { OR }^{\mathrm{a}} \\
(95 \% \mathrm{CI})\end{array}$ & \\
\hline $\begin{array}{l}\text { Total } \\
\text { preserved } \\
\text { foods }\end{array}$ & & $\mathrm{p}<0.001$ & & $\mathrm{p}<0.001$ & & $\mathrm{p}=0.004$ & \\
\hline$\leq 13.5$ & $\begin{array}{c}210 \\
(42.0 \%)\end{array}$ & 1 & $\begin{array}{c}97 \\
(38.8 \%)\end{array}$ & 1 & $\begin{array}{c}31 \\
(38.8 \%)\end{array}$ & 1 & $\begin{array}{c}247 \\
(49.4 \%)\end{array}$ \\
\hline$>13.5$ & $\begin{array}{c}290 \\
(58.0 \%)\end{array}$ & $\begin{array}{c}1.78 \\
(1.35,2.34)\end{array}$ & $\begin{array}{c}153 \\
(61.2 \%)\end{array}$ & $\begin{array}{c}2.11 \\
(1.50,2.98)\end{array}$ & $\begin{array}{c}49 \\
(61.3 \%)\end{array}$ & $\begin{array}{c}2.15 \\
(1.27,3.62)\end{array}$ & $\begin{array}{c}253 \\
(50.6 \%)\end{array}$ \\
\hline $\begin{array}{l}\text { Preserved } \\
\text { vegetables }\end{array}$ & & $\mathrm{p}<0.001$ & & $\mathrm{p}<0.001$ & & $\mathrm{p}<0.001$ & \\
\hline$\leq 2.0$ & $\begin{array}{c}164 \\
(32.8 \%)\end{array}$ & 1 & $\begin{array}{c}77 \\
(30.8 \%)\end{array}$ & 1 & $\begin{array}{c}25 \\
(31.3 \%)\end{array}$ & 1 & $\begin{array}{c}265 \\
(53.0 \%)\end{array}$ \\
\hline$>2.0$ & $\begin{array}{c}336 \\
(67.2 \%)\end{array}$ & $\begin{array}{c}2.85 \\
(2.16,3.77)\end{array}$ & $\begin{array}{c}173 \\
(69.2 \%)\end{array}$ & $\begin{array}{c}3.27 \\
(2.29,4.67)\end{array}$ & $\begin{array}{c}55 \\
(68.8 \%)\end{array}$ & $\begin{array}{c}3.46 \\
(1.99,6.00)\end{array}$ & $\begin{array}{c}235 \\
(47.0 \%)\end{array}$ \\
\hline $\begin{array}{l}\text { Preserved } \\
\text { meats }\end{array}$ & & $\mathrm{p}=0.002$ & & $\mathrm{p}<0.001$ & & $\mathrm{p}=0.927$ & \\
\hline$\leq 9.0$ & $\begin{array}{c}250 \\
(50.0 \%)\end{array}$ & 1 & $\begin{array}{c}112 \\
(44.8 \%)\end{array}$ & 1 & $\begin{array}{c}49 \\
(61.3 \%)\end{array}$ & 1 & $\begin{array}{c}282 \\
(56.4 \%)\end{array}$ \\
\hline$>9.0$ & $\begin{array}{c}250 \\
(50.0 \%)\end{array}$ & $\begin{array}{c}1.52 \\
(1.16,1.99)\end{array}$ & $\begin{array}{c}138 \\
(55.2 \%)\end{array}$ & $\begin{array}{c}1.97 \\
(1.41,2.76)\end{array}$ & $\begin{array}{c}31 \\
(38.8 \%)\end{array}$ & $\begin{array}{c}0.98 \\
(0.58,1.64)\end{array}$ & $\begin{array}{c}218 \\
(43.6 \%)\end{array}$ \\
\hline
\end{tabular}


${ }^{a}$ From separate logistic regression models adjusting for age (years), body mass index (5 years ago, $\mathrm{kg} / \mathrm{m}^{2}$ ), physical activity (MET-hours/week), total energy intake (kcal/day), parity, oral contraceptive use (never, ever), menopausal status (pre, post), marital status (never married, married, widowed/divorced/separated), education level (none/primary, secondary, vocational/tertiary), smoking status (never, ever), alcohol drinking (no, yes), and family history of ovarian or breast cancer (no, yes). 